\title{
Measurement and Modeling of Algal Biokinetics in Highly Eutrophic Waters
}

April, 2006

\section{William T. Stringfellow}

Sharon E. Borglin

Jeremy S. Hanlon

Ecology Department

Earth Sciences Division

Berkeley National Laboratory

1 Cyclotron Road, MS 70A-3317

Berkeley, CA 94720 


\section{Introduction}

Algae are now recognized as a significant source of organic carbon in the San Joaquin River (SJR) between Lander Avenue and the Stockton Deepwater Ship Channel. Algal grow to high concentrations in the SJR because it is a shallow, warm, and nutrient rich ecosystem. Large standing crops of algae can support higher trophic level productivity, but large algae blooms can also impair water quality. Algae and algal exudates can contribute taste and odors to drinking water, form disinfection by-products upon chlorination, clog filters, and otherwise degrade the quality and usefulness of a drinking water source.

A report from the Regional Board concluded that excessive algal growth was impairing water quality in the SJR. In this report it was postulated that algal blooms in the river could be mitigated if the amount of algae entering the river from tributaries was reduced (Foe et al. 2002). The mechanism by which algal inoculum to the river from the tributaries might be controlled is unknown and this study was conducted to gather basic scientific information concerning algal growth kinetics in a major tributary of the SJR, the San Luis Drain (SLD). Understanding growth kinetics and the processes of algal growth in the tributaries is a first step toward the development of a system wide understanding of algae growth in the river ecosystem.

The SLD is a significant collection point for agricultural drainage entering the San Joaquin River. The SLD is used by the Grasslands Bypass Project to convey agricultural drainage from the Grassland Drainage Area (GDA) to the SJR. Algae grow in the nutrient rich drain water during this conveyance. The GDA consists of seven water and drainage districts that collectively deliver drainage to the SLD at a connection point south of Dos Palos. In the SLD, the drainage is transported north approximately 28 miles, through the Grassland Water District, until it discharges into Mud Slough. Flow and electrical conductivity (EC) are measured continuously at the entrance and exit of the drain by the Grassland Area Drainers.

Prior studies have shown that significant algal growth occurs between the entrance and exit of the drain (Stringfellow and Quinn 2002). It has also been shown that the Mud Slough, through which the SLD discharges, is a significant source of algal inoculum to the SJR, contributing up to $7 \%$ of the Maze Boulevard chlorophyll load (Foe et al. 2002). The entry to the SLD could be considered as a location for sediment, nutrient, and selenium treatment facilities. Information about the growth and fate of algae in the SLD will help determine whether removal of nutrients that support algae growth or of algae at any such treatment site may be an appropriate strategy.

The configuration of the drain makes it an ideal location for meso-scale field experiments. The SLD is an open, shallow, concrete lined channel that is fully exposed to sunlight and warm temperatures. A controlled inlet introduces subsurface agricultural drainage at a maximum rate that was set based on a selenium reduction total maximum daily load (TMDL). This flow rate was set considerably less that the design flow rate of the facility thus resulting in relatively slow velocities in the drain. There is also groundwater accretion into the drain that occurs during the winter months of the year. There are no additional hydrologic inputs to the drain between the entrance and exit, 
making the system ideal for controlled studies. During the summer, agricultural drainage takes approximately three days to travel the length of the drain.

Algal growth in agricultural drains and the San Joaquin River is typically assumed to be limited only by the available daylight, because these waters are high in nitrogen and minerals such as ortho-phosphate which are required for algal growth (Foe et al. 2002). It was predicted that algal growth in nutrient rich agricultural drains and the San Joaquin River would follow an unlimited growth model. A common unlimited growth model is the exponential growth model

$$
X_{t}=X_{0} e^{(\mu t)} \quad \text { Eq. } 1
$$

where $X_{t}$ the algal biomass in the river at time $t, X_{0}$ is the initial algal biomass, $\mu$ is the apparent algal growth rate, and $t$ is the elapsed residence time in the river.

The implication of this model is that control or treatment of algal sources $\left(X_{0}\right)$ would benefit water quality in the river. For example, as shown in Figure 1, if the exponential model were descriptive of algal growth, a 90\% reduction of algal biomass at one location would result in a significant impact on algal biomass downstream. Based on this model, control of algal at the entrance to the SLD could be an effective way to reduce algal load at the exit of the drain. Furthermore, reduction in algae inoculum to the river from the SLD would result in a reduction of algal load in the main-stem of the SJR, if the unlimited model also held true for the river.

As part of this research, it was proposed that an alternative model may be more applicable to algal growth in agricultural drains and in the SJR. In this model, algal growth is initially exponential, but eventually the algal biomass accumulates to a maximum level, or carrying capacity (K), where growth is limited by an environmental parameter, such as nutrients or crowding. A common form of this population model is the logistic model:

$$
N_{t}=\frac{K}{1+\left[\frac{K-N_{o}}{N_{o}}\right] e^{-r t}}
$$

where $N_{t}$ is the concentration of algae at time $t, N_{0}$ is the initial concentration of algae, $K$ is the maximum algae concentration the ecosystem will support, $r$ is the algal growth rate, and $t$ is the elapsed time.

The implication of this model is that control or treatment of algal sources $\left(N_{0}\right)$ would not necessarily benefit water quality in the river. For example, as shown in Figure 2 , if the logistic model were descriptive of algal growth, a $90 \%$ reduction of algal biomass at one location would not necessarily result in a significant impact on algal biomass at some distant location downstream. In the case of the logistic relationship, a more effective control strategy would be to identify the limiting condition and manipulate that condition to reduce algal growth. For example, if phosphate is found to be limiting, 
a phosphate control program would be more effective at reducing algal pollution than a program to control algal discharges directly.

A primary objective of this project was to determine if algal growth in the SLD followed an unlimited population model (such as eq. 1) or a limited model (such as eq. 2). If the limited model was more descriptive of algal growth, then a mechanistic model would be developed to attempt to determine what environmental parameters are controlling algal growth yield in the SLD. A better understanding of the growth of algae in the SLD can then be used to evaluate algal control measures for this region. In this final report, we present our findings concerning how algal growth patterns in the SLD correspond to known population models and mechanistic models of algal growth.

\section{Methods}

Field measurements were made with handheld sondes and water quality measurement devices, including a YSI 6600 sonde, HACH turbidometer, and Myron combination Ultraprobe. For dye studies, Hydrolab combination sondes were used. Handheld probes were calibrated daily before each use and continuous monitoring devices were calibrated and deployed according to the manufacturer's specifications. Confirmation (QC) of continuous measurements were performed using replicate sampling for laboratory analysis and duplicate calibrated instruments, as required. Flow measurements were provided by the Grassland Area Drainers.

Grab samples were taken from bridges and check structures along the length of the drain (Figure 3). Samples were taken approximately in mid-stream and were depth integrated. Residence time in the SLD was calculated using velocity measurements in combination with dye studies (Table 1).

Samples collected in the field were transported to Berkeley National Laboratory for analysis. All analyses were run within the allowed holding time applicable to the preservation method used (APHA 1998). Total organic carbon (TOC) was measured by high temperature combustion according to SM 5310 B. Dissolved organic carbon was measured on split samples after filtration through a GF/F glass fiber filter (or equivalent) by the same method. Total suspended solids (TSS) and volatile suspended solids (VSS) were analyzed by SM 2540 D and E, respectively. Chlorophyll-a (chl-a) and pheophytina (pha-a) were extracted and analyzed using spectrophotometric absorption (SM $10200 \mathrm{H})$. Alterative and supplementary measurements will also include EPA Method 466.0 (In-Vitro Determination of Chlorophylls) and the high performance liquid chromatographic method (EPA Method 447.0 or SM 10200H).

Ortho-phosphate was determined on samples filtered through a $0.45 \mathrm{~mm}$ Nuclepore membrane filter (filters are pre-rinsed with sample). Ortho-phosphate and total phosphorous were quantified by the Ascorbic Acid Method (adapted from SM 4500$\mathrm{P}-\mathrm{E})$. Total phosphorus was determined on non-filtered samples following persulfate digestion. Total iron was determined by the Phenanthroline Method (SM 3500-Fe B).

Experimental data were fit to population models using Grapher software (Golden Software, Golden, CO). Mechanistic models were written in Excel software and parameter estimates were generated by minimization of least-square difference between chlorophyll data and model predictions. 


\section{Results and Discussion}

Lagrangian studies were conducted along the length of the drain at different times of the year. The drain was modeled as a plug flow reactor and distance along the drain was related to residence time by measuring flow velocity and dye travel time (Table 1). The chlorophyll concentration was plotted as a function of residence time and the two models (eq. 1 and 2) were fit to the data. The results of this analysis (Figure 4) show that the logistic model gives a more consistent and accurate description of the observed algal growth data than the exponential model. The analysis of this system using the logistic model suggests that algae reach a maximum carrying capacity $(\mathrm{K})$ in this system and that the maximum amount of algae biomass that can be supported on this drain water corresponds to less than $200 \mathrm{ug} / \mathrm{L}$ of chlorophyll- $a$. Table 2 gives the best-fit parameters for the logistic model.

The irrigation season (April to September) is the most critical period for algae growth in the region and the best estimates $\left(r^{2}>0.90\right)$ of algal growth rates using the logistic model range between 0.02 and $0.06 \mathrm{~h}^{-1}$ (Table 2). These growth rates correspond to cell doubling times as high as once every $11 \mathrm{~h}$. These growth rates are on the high end of literature values (Bowie et al 1989), and it was of interest to confirm these estimates using other techniques.

Utilization of accurate algal growth rates is key to the development of accurate models for algae growth in the SLD and in the San Joaquin River regionally. It is important to gain independent verification of growth rate estimates and to make direct measurements of algal growth rates in-situ and independently of model parameter fitting routines. A direct in-situ measurement of growth rate $(\mu)$ can be made by plotting the natural-log of the algal biomass concentration against time and fitting the linear portion of the curve. The linear portion corresponds to the period of exponential doubling, which only occurs in the presence of excess nutrients, and the slope is equal to the $\mu$ for those conditions of $\mathrm{pH}$ and temperature. The in-situ measurement of $\mu$ is a measurement of net growth rate and includes losses from factors such as grazing, if they exist (see below). Table 3 presents the in-situ measurements of $\mu$ using the data shown in Figure 4 and the corresponding temperatures for those measurements. These data correspond to the same range as estimates of $r$, further confirming the logistic model is an applicable model to this system.

The relationship between temperature and $\mu$ was examined and the change in $\mu$ as a function of temperature could be reasonably predicted by the use of the Arrhenius equation. In-situ measurement of $\mu$ made at $26.4^{\circ} \mathrm{C}$ was considered the best measurement and was used as a reference temperature for fitting the Arrhenius equation, yielding a predicted doubling of activity with every increase in temperature of approximately $8^{\circ} \mathrm{C}$. This relationship between temperature and activity was incorporated into the mechanistic model, as described below. Correction of the observed $\mu$ to $26^{\circ} \mathrm{C}$ yields very consistent values for the irrigation season data, suggesting that algae growth rates in the drain may be approaching maximum growth rates $\left(\mu_{\max }\right)$, which are the intrinsic biological limit to cell doubling. In-situ measurements confirm that algae in this system can double their 
mass at least as fast as once every $17 \mathrm{~h}$, even if significant losses due to grazing are occurring.

Several environmental parameters that could potentially influence algal growth were evaluated, including light availability, temperature, $\mathrm{pH}$, inorganic carbon concentration, nutrient concentration, and mineral availability. Day length and measurements of solar radiation at local weather stations were evaluated for a relationship to $r, K$, and $\mu$ (least-squares regression and plotting) and were not found to be a controlling factor for algae growth in the SLD independent of temperature.

Direct measurements of incident photosynthetically active radiation (PAR) and PAR attenuation with depth in the SLD were made using quantum light detectors. Total suspended solids (TSS) concentrations decline along the length of the drain, due to settling losses, while volatile suspended solids (VSS) concentrations increase due to algae growth (Figure 5). The removal of mineral solids (TSS minus VSS) has a more significant effect on light attenuation than the increase in algal biomass and as a result there is more available light at the last third of the SLD, where net algal growth rates are typically low or negative, than at the second third of the drain, where algae growth rates are typically highest (Figure 6). This observation that this change in PAR attenuation is not correlated positively with algal growth rates is direct evidence that this system is not light limited.

The logistic model describes how a populations may respond to growth limiting conditions, however the model provides no mechanistic explanation as to what factors are limiting growth. A modeling approach was used to evaluate the importance of temperature, $\mathrm{pH}$, inorganic carbon, nutrient concentration, and mineral availability on algae growth in the SLD. A mechanistic model was written using procedures detailed in Bowie et al. (1985) as follows:

$$
\begin{array}{lr}
X_{2}=X_{1} e^{(\mu+g)\left(t_{2}-t_{1}\right)} & \text { Eq. } 3 \\
\mu=f(T) f(L) \mu_{\max } & \text { Eq. } 4 \\
g=f(T) f(Z) g_{\max } & \text { Eq. } 5 \\
f(T)=2^{(0.138(\mathrm{~T}-26))} & \text { Eq. } 6 \\
f(L)=\min [f(M), f(P), f(C), f(N)] & \text { Eq. } 7 \\
f(M)=\frac{M}{M+K_{s m}} & \text { Eq. } 8 \\
f(P)=\frac{P}{P+K_{s p}} & \text { Eq. } 9
\end{array}
$$




$$
\begin{array}{ll}
f(C)=\frac{C}{C+K_{s c}} & \text { Eq. } 10 \\
C=\left(\frac{\left[H^{+}\right]}{\left[H^{+}\right]^{2}+\left[H^{+}\right] 10^{-6.4}+10^{-16.7}}\right) 100 & \text { Eq. } 11 \\
f(N)=\frac{N}{N+K_{s n}} & \text { Eq. } 12 \\
f(Z)=\frac{X_{1}}{X_{1}+K_{s z}} & \text { Eq. } 13
\end{array}
$$

where $X_{1}$ equals initial biomass at time $1\left(t_{1}\right)$ measured as chlorophyll $a, X_{2}$ equals biomass at time $2\left(t_{2}\right)$ measured as chlorophyll $a, \mu$ is the algal growth rate, $g$ is the rate of algal grazing (negative number describing algal loss due to grazing). The observed growth rate, $\mu$, is a function of the inherent maximum growth rate $\left(\mu_{\max }\right)$, environmental temperature (T), and the most severely limiting factor of either mineral concentration (M) as measured by suspended mineral solids (TSS minus VSS), carbon dioxide expressed as a percent of total dissolved inorganic carbon (C), nitrate-nitrogen $(\mathrm{N})$ or ortho-phosphate (P) concentration. The temperature modification factor $(f(T))$ was developed from the Arrhenius equation using observed maximum growth rates calculated by the natural-log plot method as described above. Other factors are based on the Michaelis-Menten relationship (Bowie et al. 1985), where $K_{s m}, K_{s p}, K_{s c}, K_{s n}$, and $K_{s z}$ are the half-saturation constants for minerals, ortho-phosphate, carbon dioxide, nitrate, and grazing, respectively. The observed grazing rate, $g$, is a function of the inherent maximum algal grazing rate $\left(g_{\max }\right)$, temperature, and the density of algal biomass $\left(X_{I}\right)$ as measured by chlorophyll $a$.

Analysis of the available data using this model suggests that algal growth in the drain can be described as a function of phosphate concentration, mineral concentration, carbon dioxide solubility, and grazing pressures (Figure 5). Nitrogen is always in excess

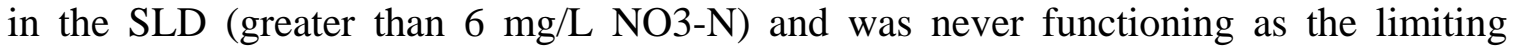
nutrient. Least-squares regression between the predicted and actual values, using the parameters listed in Table 4, yields an $\mathrm{r}^{2}$ of 0.942 . The model describes the warm weather data better than the winter data (Julian day 13), this may be due to the Arrheniustype temperature correction factor overestimating algal growth rates or underestimating zooplankton grazing rates in the winter or a shift in algal population between the winter and summer months.

This model offers important insight into factors that limit to algal population growth. Analysis of the data using the model suggests that phosphate is the most important limiting factor, being the most limiting nutrient the majority of the time (54\% of all cases tested). The model results demonstrate a positive relation between suspended 
mineral solids concentration and algal growth rate, indicating that suspended mineral solids are positive influence on algal growth in the SLD. This result suggests a departure from current thinking on the issue, since suspended mineral solids typically are expected to inhibit algal growth (via light attenuation), not act as a source or reservoir for mineral nutrients stimulatory to algal growth. In this model, mineral solids may be functioning as a surrogate for a number of trace minerals required by algae. For example, there is a correlation between mineral solids concentrations and total iron in the San Joaquin River ecosystem $\left(r^{2}=0.786\right)$. Mineral solids concentrations can also be correlated with other nutrient metals and silica, an important nutrient for the diatoms growing in the drain.

Two other factor apparently limiting growth, identified using the model, are carbon dioxide solubility and zooplankton grazing. Photosynthetic activity removes carbon dioxide and induces alkaline shifts in $\mathrm{pH}$. In approximately $25 \%$ of the cases tested, carbon dioxide solubility (calculated as a percent of total inorganic carbon) was identified as the factor limiting algal growth. It is likely the rise in $\mathrm{pH}$ is limiting the availability of soluble carbon dioxide to the algae during periods of particularly vigorous growth.

A density dependent decay component is needed to describe the decline of algae biomass at the end of the drain, which typically begins after sixty hours of residence time in the drain. The decline in biomass could not be characterized using a fixed intrinsic decay constant or settling function to describe algal losses. Lipid analysis confirmed the presence of a significant zooplankton population, supporting the supposition that zooplankton grazing is a significant environmental parameter effecting algal carrying capacity in the drain.

The results of this research indicate that algal growth in the SLD is an environmentally limited process and therefore control of environmental factors, such as nutrient or mineral availability, would be a more successful approach for reducing the growth of algae in tributaries to the SJR than controls aimed at reducing algae concentrations directly. Since growth often follows a limited model, there is not always a direct relationship between entrance algae concentration and exit algae concentration on the SLD. The positive impact of suspended mineral sediments on algae blooms suggests that removal of sediments from nutrient rich agricultural drainage could reduce the growth of suspended algae in tributaries and rivers.

\section{References}

American Public Health Association (APHA). 1998. Standard Methods for the Examination of Water and Wastewater, 20th Edition. American Public Health Association, Washington, DC.

Bowie, G. L., W. B. Mills, D. B. Porcella, C. L. Campbell, J. R. Pagenkopf, G. L. Rupp, K. M. Johnson, P. W. H. Chan, S. A. Gherini, and C. E. Chamberlin. 1985. Rates, Constants, and Kinetic Formulations in Surface Water Quality Modeling (2 ${ }^{\text {nd }}$ edition). Office of Research and Development, U.S. Environmental Protection Agency, Athens, GA. EPA/600/3-85/040. 
Foe, C., M. Gowdy, and M. McCarthy. 2002. Draft Strawman Allocation of Responsibility Report. California Regional Water Quality Control Board Central Valley Region, Rancho Cordova, CA.

Stringfellow, W. T. and N. W. T. Quinn. 2002. Discriminating Between West-Side Sources of Nutrients and Organic Carbon Contributing to Algal Growth and Oxygen Demand in the San Joaquin River. CALFED Bay-Delta Program, Sacramento, CA. Ernest Orlando Lawrence Berkeley National Laboratory Formal Report No. LBNL-51166. Berkeley National Laboratory, Berkeley, CA. 
Table 1: Sampling points and related information where field measurements and grab samples were collected.

\begin{tabular}{|c|c|c|c|c|c|}
\hline Sampling Points & $\begin{array}{l}\text { Distance } \\
\text { mile }\end{array}$ & $\begin{array}{c}\text { Hydraulic } \\
\text { residence } \\
\text { time } \\
\text { (hrs) }\end{array}$ & $\begin{array}{c}\text { USBR } \\
\text { Drain } \\
\text { mileage }\end{array}$ & $\begin{array}{c}\text { Longitude } \\
\text { North }\end{array}$ & $\begin{array}{c}\text { Latitude } \\
\text { West }\end{array}$ \\
\hline SLD Entrance & 0.00 & 0.00 & 105.15 & 36.954 & -120.663 \\
\hline Check 18 & 0.40 & 0.68 & 104.75 & 36.960 & -120.663 \\
\hline Check 17 (Site A) & 1.08 & 1.88 & 104.07 & 36.967 & -120.671 \\
\hline Check 16 & 2.76 & 5.15 & 102.39 & 36.983 & -120.690 \\
\hline Check 15 & 3.72 & 7.22 & 101.43 & 36.989 & -120.705 \\
\hline Check 14 & 5.06 & 10.33 & 100.09 & 37.000 & -120.724 \\
\hline Check 13 & 5.97 & 12.60 & 99.18 & 37.007 & -120.738 \\
\hline Check 12 & 6.43 & 13.80 & 98.72 & 37.011 & -120.744 \\
\hline Check 11 & 8.93 & 20.86 & 96.22 & 37.039 & -120.772 \\
\hline Check 10 & 10.39 & 25.43 & 94.76 & 37.055 & -120.788 \\
\hline Check 9 & 12.49 & 32.56 & 92.66 & 37.072 & -120.803 \\
\hline Check 8 & 14.06 & 38.33 & 91.09 & 37.100 & -120.822 \\
\hline Check 7 & 14.51 & 40.06 & 90.64 & 37.106 & -120.820 \\
\hline Check 6 & 16.34 & 47.38 & 88.81 & 37.118 & -120.818 \\
\hline Check 5 & 17.40 & 51.86 & 87.75 & 37.147 & -120.824 \\
\hline Check 4 & 19.20 & 59.85 & 85.95 & 37.177 & -120.833 \\
\hline Check 3 & 21.77 & 72.11 & 83.38 & 37.208 & -120.846 \\
\hline Check 2 & 22.05 & 73.51 & 83.1 & 37.215 & -120.851 \\
\hline Check 1 & 23.87 & 82.88 & 81.28 & 37.231 & -120.876 \\
\hline SLD End (Site B) & 26.52 & 97.42 & 78.63 & 37.261 & -120.905 \\
\hline
\end{tabular}


Table 2. Best fit parameters for the logistic model (eq. 2) to observed algal growth patterns in the SLD.

\begin{tabular}{lccccc}
\hline Date & Day of year & $\boldsymbol{N}_{\boldsymbol{o}}$ & $\boldsymbol{K}$ & $\boldsymbol{r}$ & $\mathbf{r}^{\mathbf{2}}$ \\
\hline $01 / 13 / 05$ & 13 & 6.71 & 10.50 & 0.023 & 0.971 \\
$05 / 13 / 04$ & 134 & 19.02 & 203.00 & 0.023 & 0.936 \\
$06 / 17 / 03$ & 168 & 19.90 & 123.90 & 0.219 & 0.745 \\
$07 / 13 / 04$ & 195 & 36.60 & 162.10 & 0.049 & 0.922 \\
$06 / 30 / 03$ & 181 & 45.70 & 177.20 & 0.055 & 0.942 \\
$07 / 29 / 03$ & 210 & 16.60 & 142.00 & 0.062 & 0.931 \\
\hline
\end{tabular}


Table 3. Plotting the natural $\log$ of biomass over time gives a direct estimate of growth rate $(\mu)$ under excess nutrient conditions, however this method does not account for the effects of zooplankton grazing $(g)$. Estimated of $\mu$ by this methods are in the same range as estimates of growth rate $(r)$ by the logistic model further supports the applicability of the logistic model to algal growth in the drain.

\begin{tabular}{lcccccc}
\hline Date & $\begin{array}{c}\text { Day of } \\
\text { year }\end{array}$ & $\begin{array}{c}\text { Temperature } \\
\left({ }^{\mathbf{(}} \mathbf{C}\right)\end{array}$ & $\begin{array}{c}\text { Observed } \\
\boldsymbol{\mu} \\
\left(\mathbf{h}^{-1}\right)\end{array}$ & $\begin{array}{c}\boldsymbol{\mu} \\
\text { Corrected to } \\
\mathbf{2 6}^{\mathbf{0}} \mathbf{C} \\
\mathbf{( h}^{-1} \mathbf{)}\end{array}$ & $\mathbf{r}^{2}$ & $\mathbf{n}$ \\
\hline $01 / 13 / 05$ & 13 & 9.8 & 0.015 & 0.069 & 0.953 & 5 \\
$05 / 13 / 04$ & 134 & 20.0 & 0.018 & 0.031 & 0.913 & 21 \\
$06 / 17 / 03$ & 168 & 24.8 & $*$ & $*$ & $*$ & $*$ \\
$07 / 13 / 04$ & 195 & 25.7 & 0.038 & 0.040 & 0.982 & 5 \\
$06 / 30 / 03$ & 181 & 26.4 & 0.034 & 0.033 & 0.981 & 10 \\
$07 / 29 / 03$ & 210 & 27.1 & 0.033 & 0.029 & 0.984 & 7 \\
\hline
\end{tabular}

*not calculated due to insufficient data points 
Table 4. Best fit estimates for parameters included in the mechanistic model for algal growth in the San Luis Drain. See text for explanation.

\begin{tabular}{lcc}
\hline Parameter & Best fit estimate & Units \\
\hline$\mu_{\max }$ & 0.061 & $\mathrm{hr}^{-1}$ \\
$g_{\max }$ & -0.053 & $\mathrm{hr}^{-1}$ \\
$K_{s m}$ & 19.3 & $\mathrm{mg} / \mathrm{L}$ \\
$K_{s p}$ & 0.018 & $\mathrm{mg} / \mathrm{L}$ \\
$K_{s c}$ & 0.25 & $\%$ \\
$K_{s z}$ & 100 & $\mu g / \mathrm{L}$ \\
$K_{s n}$ & not estimated & $\mathrm{mg} / \mathrm{L}$ \\
\hline
\end{tabular}


Figure 1: Theoretical case where algal growth follows exponential model. Effort made to remove $90 \%$ of the algal biomass at one point in a river would have a proportional beneficial effect on algal biomass accumulation down river.

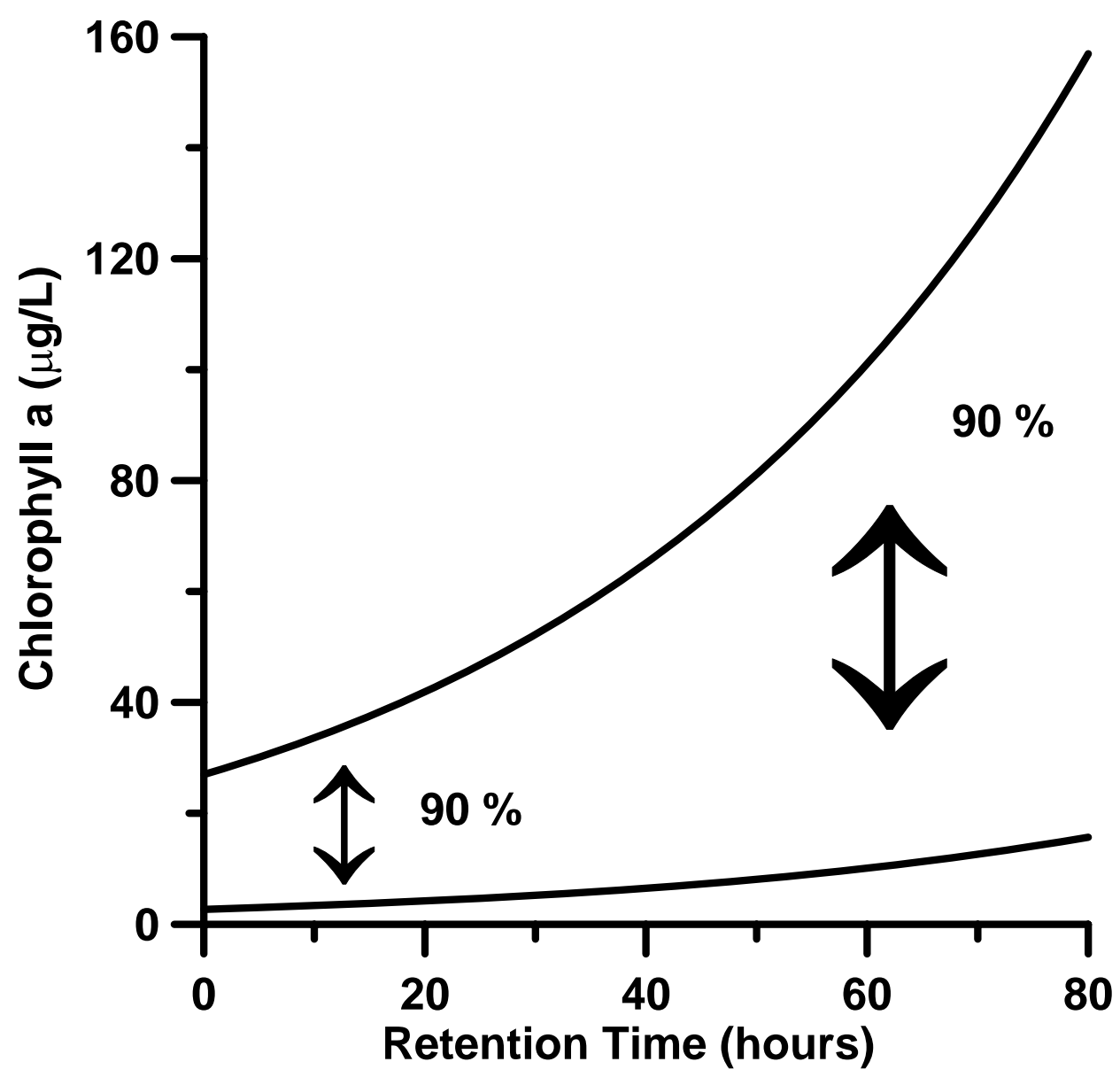


Figure 2: Theoretical case where algal growth follows logistic model. Effort made to remove $90 \%$ of the algal biomass at one point in a river may have limited effect on algal biomass accumulation down river, due to rapid growth of algae to the maximum carrying capacity of the ecosystem.

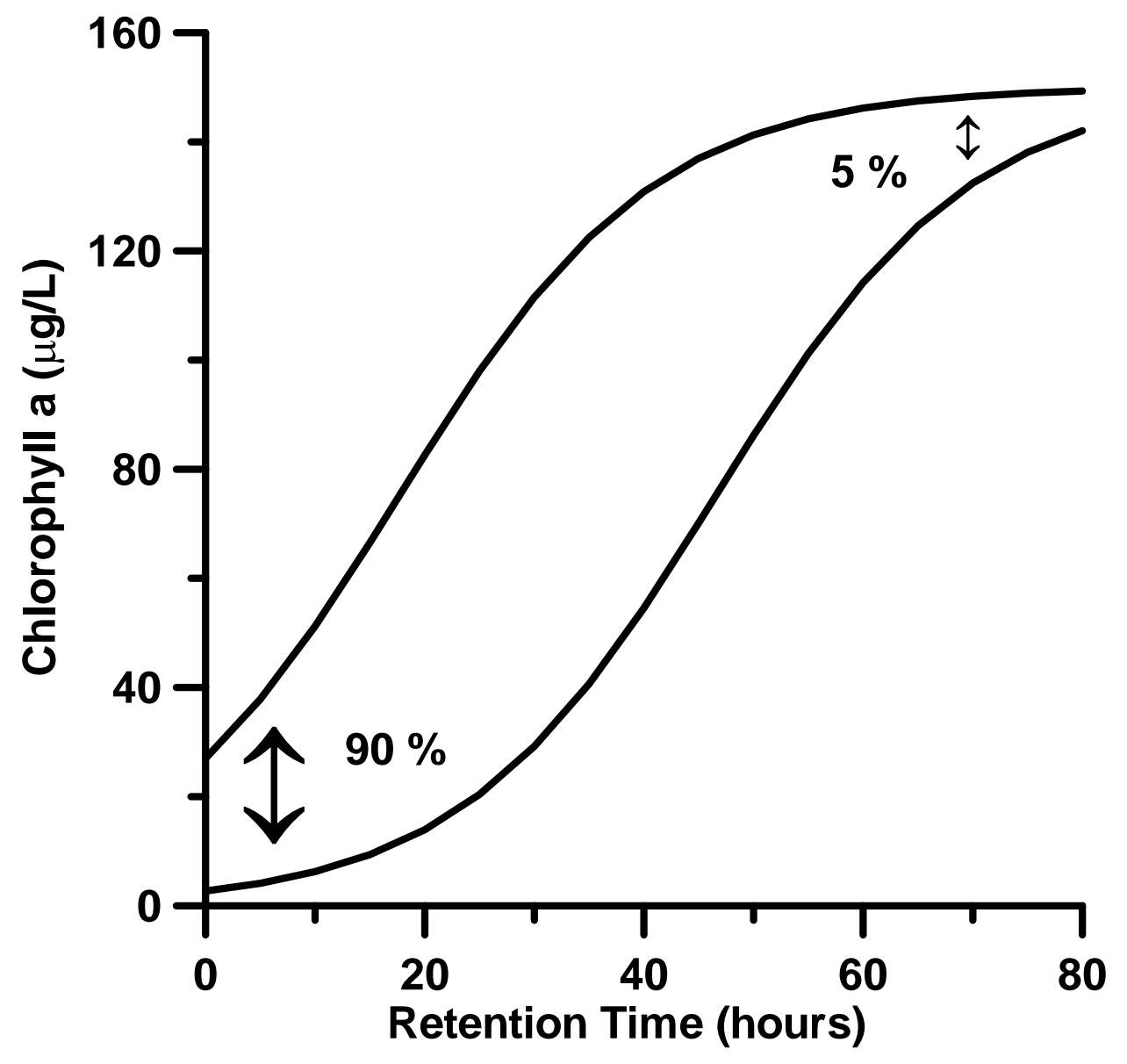


Figure 3. Map of study region. Green represents areas of native vegetation, white areas are urban, other colors are agricultural lands. Red dots are sample points (Table 2) along the San Luis Drain, represented as a blue line.

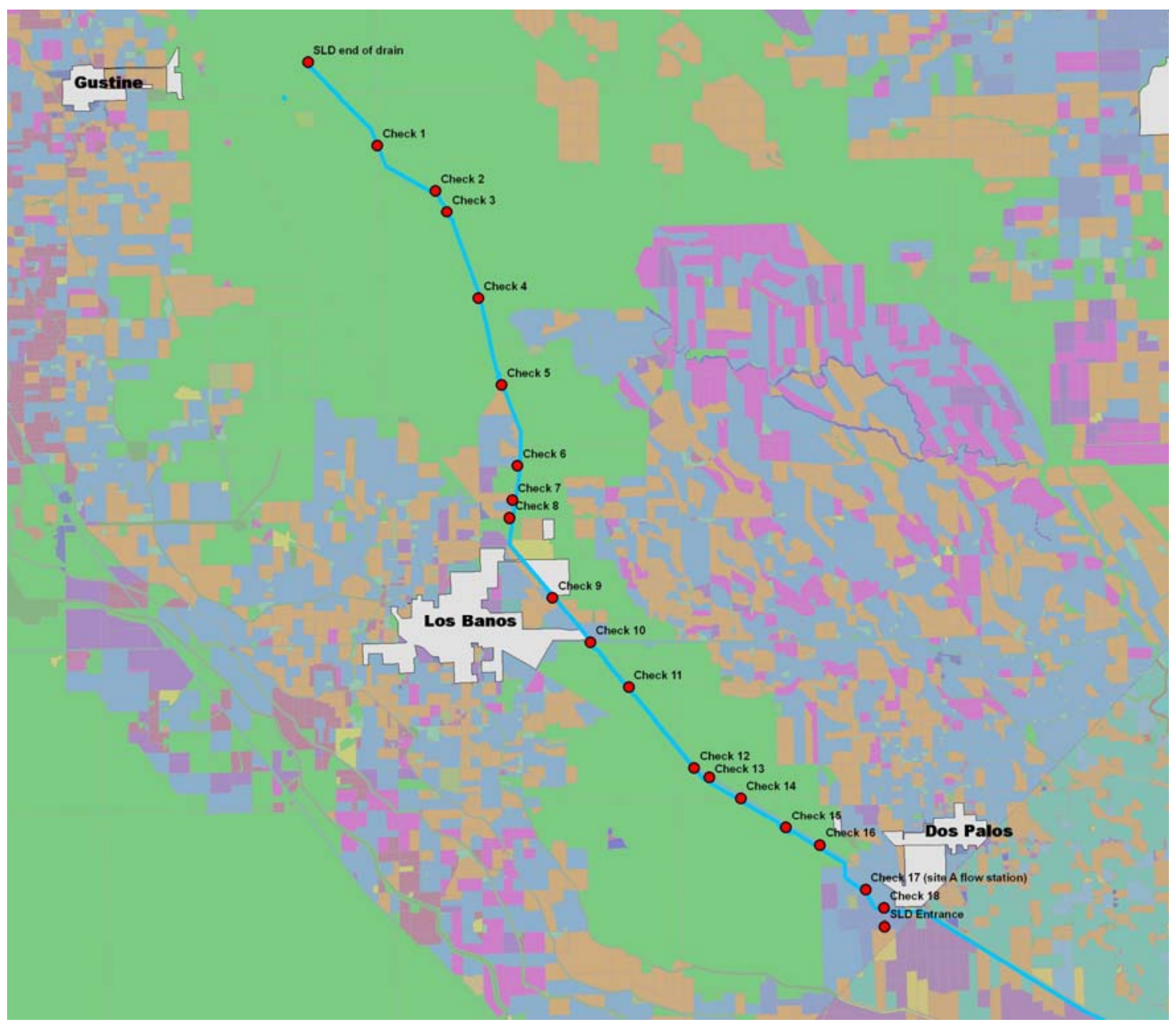


Figure 4. Lagrangian studies of the San Luis Drain (SLD) demonstrate that algal growth can be described by the Logistic model (eq. 2) and that the use of the exponential growth model (eq. 1) in most cases fails to adequately describe the true growth pattern. The logistic model does not assign a mechanistic cause, but does indicate that algal growth in the SLD is environmentally limited.
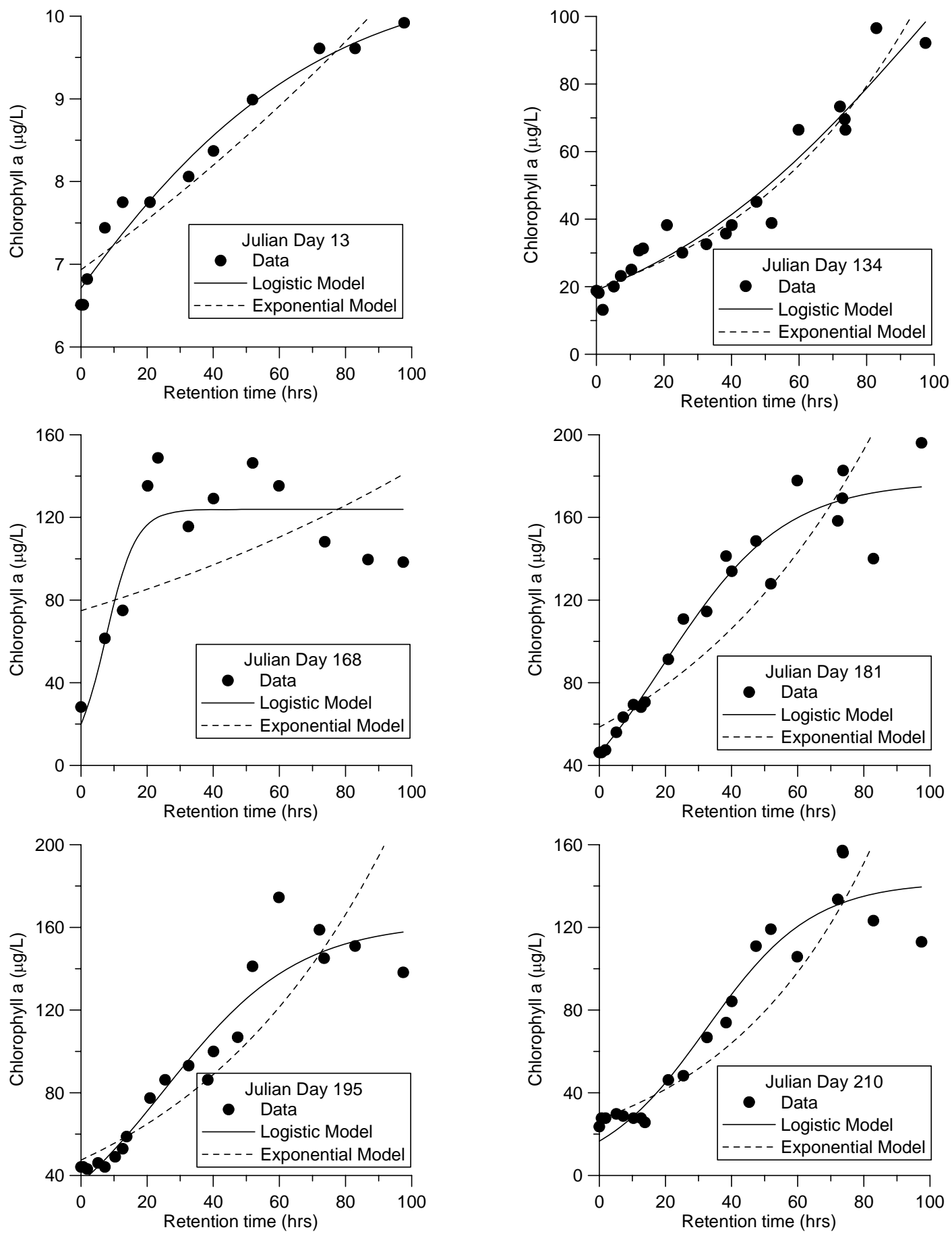
Figure 5. Total suspended solids (TSS) concentration decreases as a function of drain length. Settling of sand and larger particles occurs as the water travels down the drain. The settling of solids results in improved water clarity and better light penetration at the end of the drain (see Figure 6) despite the increase in volatile suspended solids (VSS) that occurs as a result of algal growth. Mineral solids concentration, used for mechanistic modeling, is calculated by subtracting VSS from TSS. Data for day 210 is shown.

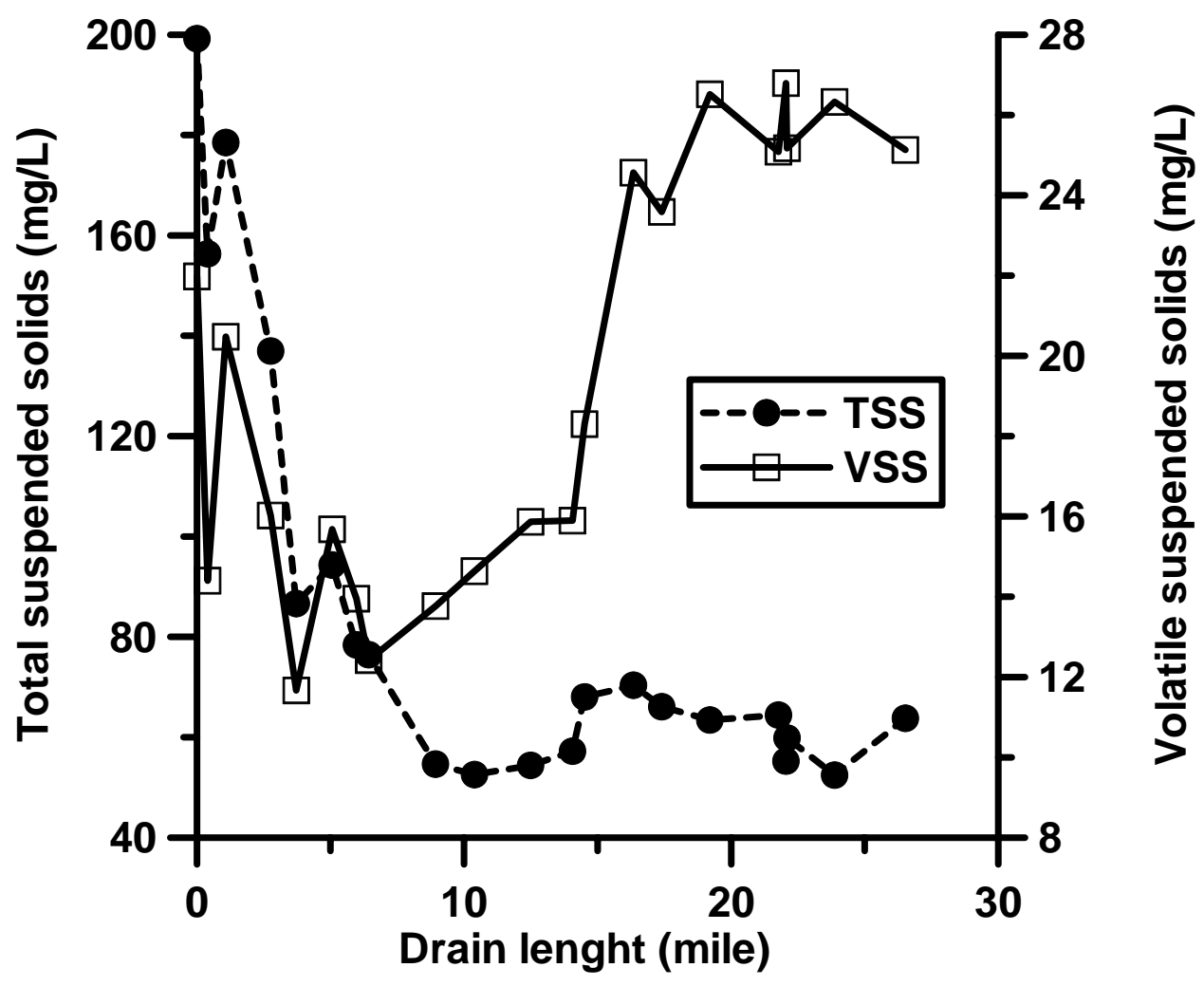


Figure 6: Penetration of incident light in the San Luis Drain. Measurement of photosynthetically active radiation (PAR) at a two-foot depth demonstrates that there is more light available at the end of the drain than the entrance. Increased light penetration corresponds to a removal of sediments along the length of the drain (Figure 5). Net algal growth rates are typically lower or negative at the end of the drain (Figure 4), suggesting that light is not the limiting factor responsible for this decline in net growth rate.

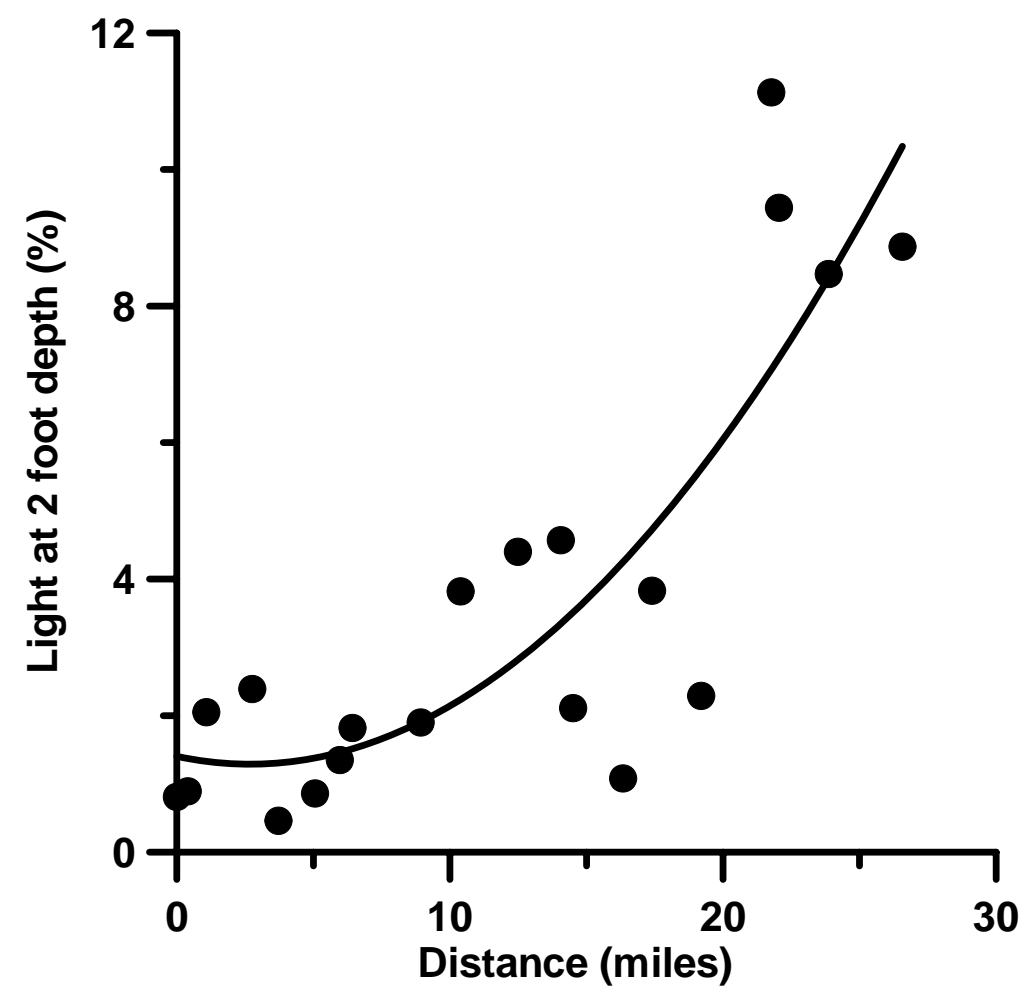


Figure 7. Combined nutrient limitation and grazing model fit to observed chlorophyll $a$ concentration in the San Luis Drain. See text for explanation.
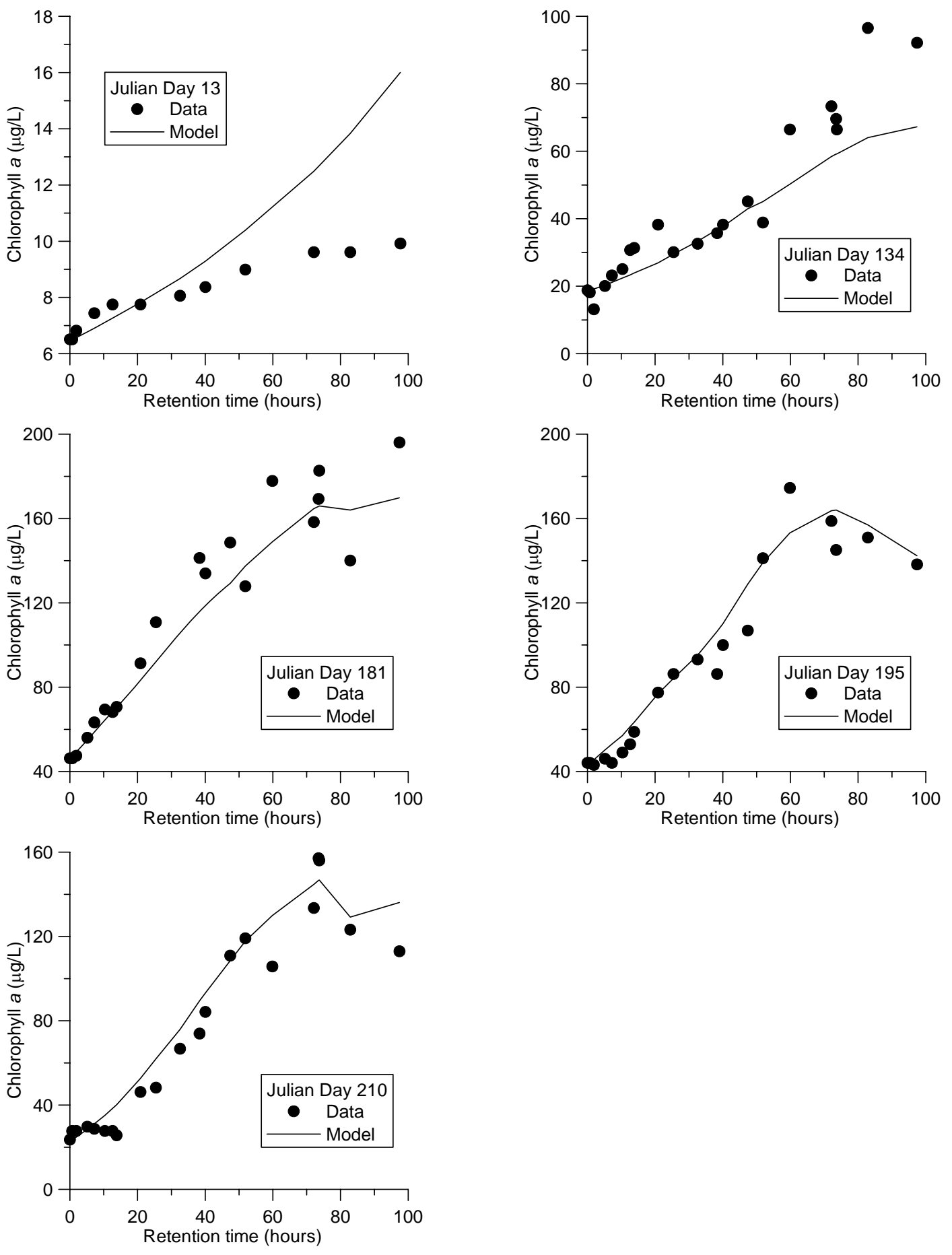